\title{
Análise crítica de experiência com redesenho de processos em um laboratório clínico
}

\author{
Critical analysis of processes redesign experience in a clinical laboratory
}

Fernando de Almeida Berlitz

\begin{abstract}
unitermos
resumo

Melhoria de processos

Introdução: Para competir no mercado atual de medicina laboratorial, há a necessidade de processos

Mapeamento de processos

com elevado nível de agregação de valor aos clientes e alta flexibilidade para atender às modificações constantes nos requisitos de clientes e legais, bem como capacidade de se adaptar às modificações

Redesenho de processos

Laboratório clínico

Pensamento enxuto

Seis Sigma

no ambiente competitivo. Esses desafios exigem uma adaptação global do laboratório para uma visão baseada em processos. Objetivo: Avaliar criticamente uma iniciativa de mapeamento e redesenho de processos desenvolvida em um laboratório clínico de grande porte. Nessa análise crítica, serão apresentados e avaliados os resultados de um projeto de redesenho realizado na área técnica da empresa, incluindo processos técnicos e de apoio. Materiais e métodos: Foram mapeados 37 processos técnicos, utilizando metodologia adaptada e identificando as principais desconexões e oportunidades de melhoria. Cada processo foi sequencialmente analisado e redesenhado e um plano de ação foi gerado para a implementação de cada novo processo. Resultados: Após a implementação dos novos processos redesenhados, a produtividade de pessoal técnico aumentou em mais de $30 \%$. Outro resultado importante foi obtido em termos de flexibilidade dos processos, principalmente em razão da nova estrutura de subáreas na área técnica. Discussão: Os principais pontos críticos do projeto estiveram relacionados com a disponibilidade de recursos de tecnologia da informação (TI) e a não priorização de medições nos processos no momento inicial do projeto. Conclusão: A iniciativa de redesenho de processos, se implementada com um roteiro planejado, orientada a resultados e alinhada à estratégia da organização, pode proporcionar resultados significativos para os laboratórios clínicos.
\end{abstract}

\section{abstract}

Introduction: In order to ensure market competitiveness in laboratory medicine, there is a current demand for processes with high customer added value, high flexibility to attend fluctuating customer and legal requirements, as well as ability to adapt to changes. These challenges require global adaptation to a processbased view. Objective: To evaluate critically an initiative of process mapping and redesigning developed in a major clinical laboratory. In this analysis, the results of the redesign project developed in the technical area are presented and evaluated, including technical and support processes. Methods: Thirty-seven technical processes were mapped by use of customized methodology, and key disconnections and improvement opportunities were identified. Each process was sequentially reviewed and redesigned. Furthermore, an action plan was outlined for the implementation of each new process. Results: After implementing new redesigned processes, staff productivity rose by over 30\%. Another important result was obtained in terms of process flexibility, mainly due to the new subarea structure in the technical area. Discussion: The main crucial points of the project were related to information technology (IT) resource availability and no prioritization of process assessment at the beginning of the project. Conclusion: Clinical laboratories may attain significant results with process redesign initiatives as long as these are result-oriented, aligned with the organization strategies and implemented with a planned approach. key words

Process improvement

Process mapping

Process redesign

Clinical laboratory

Lean thinking

Six Sigma 


\section{Introdução}

Todo trabalho importante realizado nas empresas faz parte de algum processo ${ }^{(1)}$. Não existe produto ou serviço oferecido por uma empresa sem a participação de um processo empresarial. Da mesma forma, não faz sentido existir um processo empresarial que não ofereça um produto ou um serviço ${ }^{(2)}$. Entende-se por processo a ligação direta entre a estratégia da empresa e seus recursos; processos implementam a estratégia de uma organização, utilizando os recursos disponíveis (recursos humanos, tecnológicos etc.) de forma a atender requisitos exigidos pelos clientes e/ou demais partes interessadas.

Identificar o processo como sendo a maneira típica de realizar o trabalho é importante para definir a forma básica de organização das pessoas e dos demais recursos da empresa ${ }^{(3)}$. O processo é um conceito fundamental no projeto dos meios pelos quais uma empresa pretende produzir e entregar seus produtos e serviços aos clientes.

As empresas convencionais foram projetadas em função de uma visão voltada para sua própria realidade interna, focadas em si mesmas. A implementação do ponto de vista do cliente na gestão das empresas exige que se faça o redesenho de seus processos de negócio ${ }^{(3)}$.

O laboratório clínico, muito em razão de sua missão primordial de suprir o médico com informações que apoiem o diagnóstico e o tratamento de patologias, tem histórica tendência de se organizar com base em aspectos exclusivamente técnicos. Nas áreas técnicas isso tem se manifestado em termos de setores divididos segundo diferentes disciplinas (Bioquímica, Hematologia etc.), o que muitas vezes pode comprometer a adequada utilização dos recursos disponíveis na empresa.

Nas últimas décadas, o laboratório clínico tem sido confrontado por desafios crescentes, principalmente relacionados com elevação de custos (evolução tecnológica, importação de reagentes e kits diagnósticos, atendimento de requisitos legais etc.) e dificuldade de ampliação ou manutenção das receitas (elevado poder de barganha de pagadores, que passaram até mesmo, em alguns casos, a ser concorrentes diretos dos laboratórios clínicos tradicionais do mercado de medicina laboratorial). Todos esses desafios exigiram uma nova visão de negócio por parte dos laboratórios clínicos, que passaram a buscar formas alternativas de administrar esses empreendimentos em tempos de intensa concorrência, elevado nível de consolidação e exigências sempre crescentes por parte de clientes e demais interessados.
Vários modelos têm sido propostos para ampliar a competitividade dos negócios e podem ser aplicados a diferentes setores de atuação, incluindo as empresas de medicina diagnóstica. Entre os modelos que têm sido aplicados destacam-se os com base em gestão por processos.

Os modelos de gestão por processos são desafiadores em razão de, por vezes, envolver uma transformação na cultura organizacional até então vigente; porém, tem apresentado resultados consistentes, geralmente atribuídos à visão sistêmica que agrega ao negócio, centrada no atendimento aos requisitos dos clientes e na utilização racional de recursos.

Independente de qual seja a iniciativa de melhoria a ser implantada em uma organização de saúde ou em qual metodologia esta tenha base, o essencial é que o objetivo primordial não seja esquecido ou colocado em segundo plano. O objetivo principal de qualquer melhoria de processos na área da saúde é ampliar a segurança dos serviços prestados ao paciente. Outros ganhos, financeiros ou em competitividade no mercado, mesmo que indispensáveis à sustentação do negócio (retorno do investimento realizado), devem ser entendidos como consequência das ações focadas na melhoria da segurança do paciente ${ }^{(4)}$.

Oferecer níveis elevados de segurança aos pacientes significa melhorar continuamente os processos que impactam esses clientes, garantindo estabilidade e previsibilidade a esses processos e antecipando-se a possíveis falhas, sempre que possível. Isso exige extremo conhecimento e controle de todos os processos críticos de uma organização de saúde; exige conhecer, principalmente, a complexidade dos processos e os fatores de riscos envolvidos ${ }^{(4)}$.

Para competir no mercado atual de medicina laboratorial, existe a necessidade de processos com elevado nível de agregação de valor aos clientes e com alta flexibilidade para atender às modificações constantes nos requisitos desses clientes (além de requisitos legais), bem como com capacidade de se adaptar às modificações no ambiente competitivo em que o laboratório clínico se encontra. Esses desafios exigem adequada gestão de seus processos críticos por parte do laboratório clínico e, mais do que isso, adaptação global do laboratório para uma visão com base em processos.

Em 2006, com o objetivo de obter maior agilidade e produtividade de seus processos administrativos, financeiros e de suprimentos, o laboratório iniciou um projeto visando à implantação futura do Enterprise Resource Planning (ERP), que é um sistema informatizado de planejamento dos recursos empresariais que integra as diferentes funções da 
empresa para criar operações mais eficientes ${ }^{(5)}$. O sistema de ERP integra os dados-chave e a comunicação entre as áreas da empresa, fornecendo informações detalhadas sobre as operações desta.

O projeto foi desenvolvido em parceria com uma consultoria externa e iniciou com treinamento de analistas de processos e de negócio da empresa na metodologia de Redesenho de Processos ([BPR] do inglês Business Process Redesign ou Business Process Reengineering). A abordagem de Redesenho de Processos objetiva repensar os processos empresariais, ignorando possíveis barreiras organizacionais. Nesse modelo, identificamos, acessamos e avaliamos criticamente os processos críticos atuais (desconexões, agregação de valor, desperdícios etc.), propondo um novo processo, tratando as deficiências identificadas, alinhando o processo em estudo à estratégia da empresa e aos requisitos dos clientes. A implementação de BPR deve prever suporte a mudanças radicais nos processos e estimular o pensamento criativo(6) $^{(6)}$

Após o treinamento na metodologia de BPR, a abordagem da consultoria foi adaptada para a utilização no laboratório e essa nova padronização passou a ser executada nos processos administrativos, financeiros e de suprimentos no projeto de implantação do sistema de ERP.

Paralelamento ao projeto de implantação do ERP, a metodologia da BPR passou a ser utilizada em projetos de otimização de outros processos existentes no laboratório, incluindo os técnicos (análises laboratoriais), experiência que será foco de análise neste estudo.

\section{Objetivo}

Este artigo tem como objetivo avaliar criticamente uma iniciativa de mapeamento e redesenho de processos desenvolvida em um laboratório clínico de grande porte. Nesta análise crítica serão apresentados e avaliados os resultados de um projeto realizado na área técnica da empresa, envolvendo processos técnicos e de apoio.

\section{Materiais e métodos}

Utilizando como base inicial a metodologia de Mapeamento e Redesenho de Processos disponibilizada pela consultoria externa, foi desenvolvido um modelo de aplicação dessa metodologia no laboratório. Esse modelo foi proposto pela célula de processos da área de informática do laboratório e posteriormente validado pela diretoria da empresa. O modelo padronizado para mapeamento e redesenho de processos que passou a ser utilizado em todos os projetos de redesenho de processos no laboratório é descrito na Tabela.

\section{Tabela Roteiro de aplicação da metodologia para mapeamento e redesenho de processos}

\begin{tabular}{|c|c|c|}
\hline Fases & Etapas & Atividades \\
\hline \multirow{3}{*}{$\begin{array}{l}\text { 1. Posicionamento } \\
\text { do projeto }\end{array}$} & $\begin{array}{l}\text { a) Alinhar as expectativas } \\
\text { com o patrocinador do projeto }\end{array}$ & - Identificar as questões críticas e necessidades do redesenho \\
\hline & b) Validar escopo do projeto & $\begin{array}{l}\text { - Definir alcance do projeto, metas de trabalho, projetos } \\
\text { selecionados, líderes de processos identificados (termo de } \\
\text { abertura de projeto) }\end{array}$ \\
\hline & $\begin{array}{l}\text { c) Alinhar com o gestor da } \\
\text { área/setor }\end{array}$ & $\begin{array}{l}\text { - Alinhar informações do termo de abertura de projeto com } \\
\text { gestores e direção, conforme pertinente }\end{array}$ \\
\hline $\begin{array}{l}\text { 2. Planejamento } \\
\text { do projeto }\end{array}$ & a) Planejamento & $\begin{array}{l}\text { - Estabelecer infraestrutura para mapeamento e redesenho } \\
\text { - Definir o grupo de facilitadores de mapeamento } \\
\text { - Treinar o grupo de facilitadores de mapeamento, quando } \\
\text { pertinente } \\
\text { - Realizar reunião de sensibilização para a equipe do processo } \\
\text { - Iniciar documentação do processo } \\
\text { - Analisar documentação existente referente ao processo } \\
\text { - Elaborar diagrama hierárquico-funcional (DHF) e validá-lo } \\
\text { com o patrocinador } \\
\text { - Elaborar Cronograma do projeto }\end{array}$ \\
\hline
\end{tabular}




\section{Tabela Roteiro de aplicação da metodologia para mapeamento e redesenho de processos (cont.)}

\begin{tabular}{ll}
\hline Fases & Etapas \\
\hline & $\begin{array}{l}\text { a) Reuniões de mapeamento } \\
\text { do processo "Como é" }\end{array}$
\end{tabular}

3. Definir processo atual ("Como é")

4. Preparação para o planejamento no novo processo

\section{Projeto do novo processo ("Como será")}

\section{Implantação do novo processo}

b) Documentação do processo "Como é"

c) Alinhar com patrocinador

a) Preparar facilitadores e equipe de processo

b) "Quebrando modelos mentais"

a) Reuniões "Como será"

b) Preparar documentação

c) Alinhar com gestor da área e patrocinador

d) Apresentar novo processo para a equipe

e) Recomendar alternativas sobre sistemas

a) Planejar implementação melhorias

b) Validar estratégia de implantação de melhorias

c) Implementar ações de melhoria

a) Monitorar resultados do

7. Resultados projeto

e controle

\section{Atividades}

- Elaborar documento de definição do processo

- Elaborar diagrama de contexto do processo, listando desconexões e sugestões

- Elaborar mapa de processo "Como é"

- Acessar desempenho atual do processo

- Revisar e analisar o processo atual

- Classificar e priorizar desconexões e sugestões

- Validar processos e subprocessos com equipe do processo e demais partes envolvidas

- Alinhamento dos dados obtidos com o patrocinador do projeto (diagnóstico)

- Apresentar benchmarks e melhores práticas de mercado

- Realizar novas visitas de benchmarking, quando pertinente

- Preparar equipe de processo para "pensar diferente" (preparar para mudanças)

- Preparar cenários futuros

- Elaborar nova estrutura hierárquico-funcional

- Elaborar mapas de processo "Como será"

- Alinhar projeto do novo processo com gestor e patrocinador

- Apresentar projeto do novo processo para a equipe envolvida (simulação, dramatização)

- Recomendar entre comprar novo sistema, avaliar melhor ou desenvolver internamente

- Definir estratégia de implementação das melhorias no processo atual e recursos

- Validar estratégia de redesenho do processo com patrocinador, diretoria e gestor da área

- Realizar plano de ação proposto (melhorias), implementando o novo processo

Acessar e documentar resultados (ganhos) do projeto de redesenho

Planejar e implementar o controle e o monitoramento de desempenho do novo processo
O projeto de mapeamento e redesenho de processos na central técnica do laboratório foi iniciado em março de 2007, após a aprovação junto à diretoria da empresa.

Conforme metodologia padronizada pela empresa, foi definido um patrocinador para esse projeto; para esse importante papel foi designado o diretor técnico do laboratório, médico hematologista de formação. Como coordenador do projeto foi designado um dos analistas de processos da equipe de tecnologia de informação $(\mathrm{TI})$, farmacêutico bioquímico de formação, com experiência anterior na área técnica da empresa e formação complementar em Lean Seis Sigma (Black Belt).

Na primeira fase do projeto, foram definidas questões relativas ao posicionamento do projeto; entre outros pontos foram definidos entre patrocinador e coordenação do projeto o escopo do projeto, o cronograma, as premissas 
e restrições. A partir dessas definições, foi gerado o Termo de Abertura de Projeto, documentando essa fase inicial de projeto.

$\mathrm{Na}$ fase de planejamento do projeto, foi definida a utilização de um grupo de facilitadores (todos pertencentes ao quadro de profissionais da central técnica da empresa) para trabalhar no mapeamento dos processos técnicos. Esse grupo foi definido por consenso entre coordenação do projeto e patrocinador. As premissas para a composição do grupo foram: presença de todos os níveis hierárquicos da área técnica (cargos com nível superior: gerentes, supervisores e analistas técnicos), colaboradores com experiência anterior abrangente em mais de um dos setores técnicos e colaboradores com perfil mais receptivo a mudanças (postura evidenciada em oportunidades anteriores no laboratório). $\mathrm{O}$ grupo de facilitadores foi definido com seis colaboradores - um gerente (médico), três supervisores (bioquímicos) e dois analistas técnicos (bioquímicos) - e passou a ser gerenciado pelo coordenador do projeto durante as próximas fases dessa iniciativa.

Na última semana de março de 2007, o grupo de facilitadores recebeu um treinamento de 20 horas, ministrado pelo coordenador do projeto. Esse treinamento envolveu um amplo escopo de conteúdo: gestão por processos, metodologia de mapeamento de processos, gestão de mudança, noções de lean e Seis Sigma, noções de teoria das restrições e ambiente competitivo atual do mercado de medicina laboratorial.

Após o treinamento, o grupo de facilitadores passou a realizar reuniões de mapeamento de processos ("Como é"). O primeiro passo nesse sentido foi a identificação dos processos existentes na central técnica, "descolando-os" das áreas/setores existentes. Identificaram-se 38 processos, que foram documentados em um diagrama hierárquicofuncional (DHF), conforme a Figura 1.

A seguir, em reuniões sequenciais, esses processos identificados foram mapeados pelo grupo de facilitadores com o apoio de integrantes das equipes dos processos envolvidos, sempre que necessário e pertinente. Os processos atuais ("Como é") mapeados foram condensados e documentados na forma de diagramas de contexto (Figura 2) e mapas de processo (Figura 3), utilizando-se o software iGrafx ${ }^{\circledR}$ FlowCharter 2006 (Corel Corporation).

Para cada um dos processos foram identificadas e registradas sugestões de melhoria e desconexões a serem tratadas, que seriam posteriormente integradas ao diagnóstico da área e, depois de priorizadas, utilizadas como insumo para projetar o novo processo ("Como será").

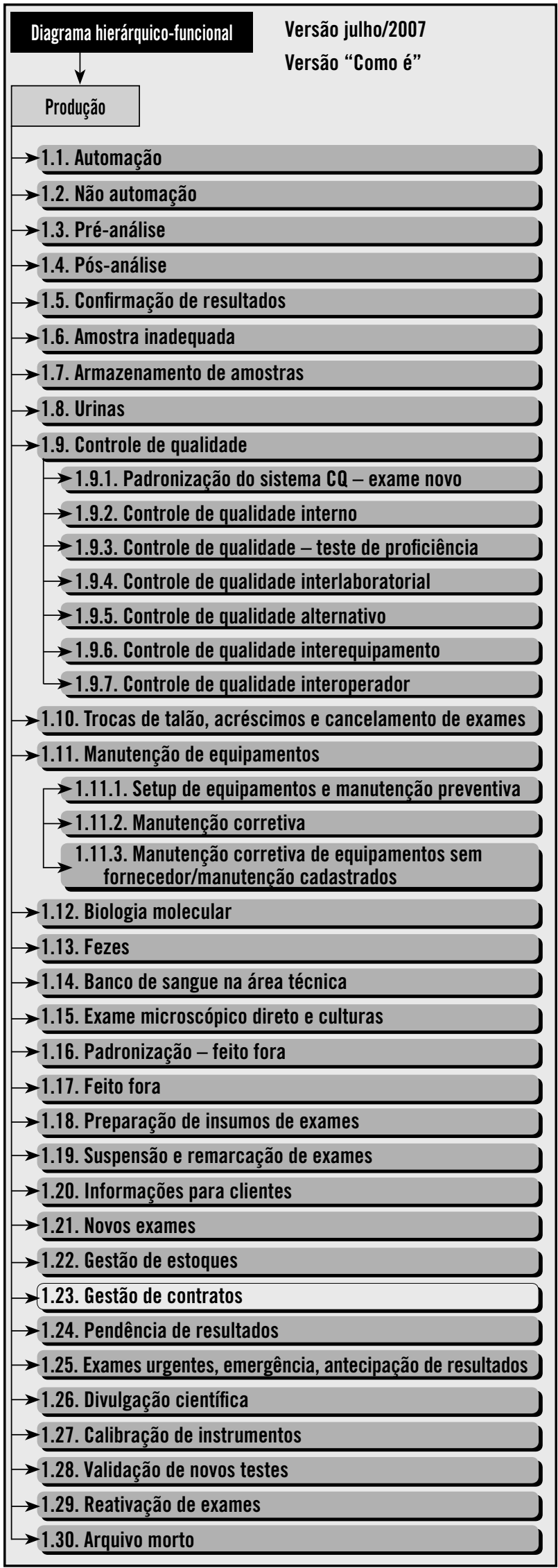

Figura 1 - Diagrama hierárquico-funcional dos processos identificados na central técnica

$C Q:$ controle de qualidade. 


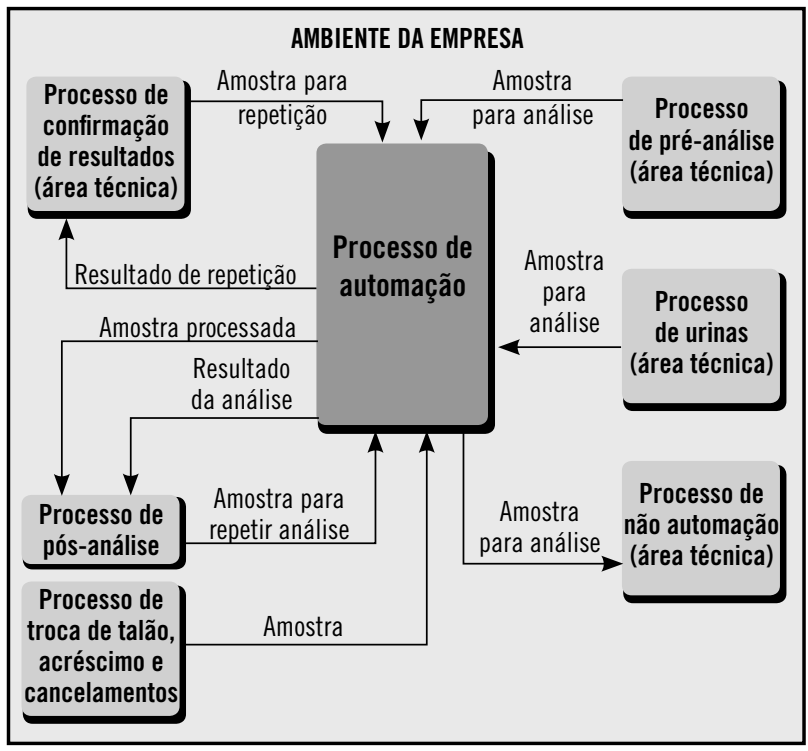

Figura 2 - Exemplo de diagrama de contexto

Após a finalização das reuniões de mapeamento dos processos atuais, as informações foram consolidadas e um diagnóstico formal foi gerado, sendo apresentado para a diretoria da empresa em julho de 2007. Ele recebeu a aprovação da diretoria, além de premissas para as próximas fases do projeto, que incluíram questões relacionadas com cronograma, e para as ações de melhoria/redesenho que têm impacto na estrutura física e no organograma da área.

Seguindo o projeto, as reuniões de projeto dos novos processos ("Como será") foram realizadas por ação/processo envolvido, de acordo com as informações originadas do mapeamento anterior dos processos atuais e com a priorização acordada entre coordenação do projeto e patrocinador. Para cada novo processo projetado, novos mapas de processo foram gerados e utilizados como base para treinamento das equipes de processo.

Os novos processos foram implementados de forma individualizada, de acordo com a finalização dos respectivos planos de ação de melhoria. A implementação dos novos processos e resultados decorrentes dessa implementação foi acompanhada em reuniões periódicas entre patrocinador e coordenador do projeto, entre janeiro de 2008 e outubro de 2009.

\section{Resultados}

\section{Resultados da fase de mapeamento dos processos atuais ("Como é")}

Durante a fase de mapeamento dos processos, foram identificados pelo grupo de facilitadores 38 diferentes processos (Figura 1). Destes, 37 foram mapeados, evidenciando as principais etapas executadas até então nesses fluxos de trabalho. O único processo identificado e não mapeado foi o de gestão de contratos, em razão de ter sido considerado pouco formalizado naquele momento para que fosse possível e necessário esse mapeamento.

As reuniões de mapeamento dos processos técnicos atuais ("Como é") foram realizadas entre abril e junho de 2007, em que o grupo de facilitadores identificou e mapeou cerca de 1,6 processos por reunião, finalizando o trabalho em 23 reuniões, cada uma com duração de duas a três horas. Esse trabalho foi complementado com a formatação dos mapas e diagramas gerados nas reuniões, pelo coordenador do projeto, em ferramenta específica (software IGrafx).

Nessas mesmas reuniões, em paralelo à geração dos mapas de processo, desconexões e sugestões referentes a cada processo eram listadas, visando gerar insumos importantes para a criação de um diagnóstico final dessa fase de mapeamento, bem como para direcionar as melhorias de processo a serem propostas. As principais desconexões globais (referentes a mais de um dos processos avaliados) identificadas nesse momento foram:

- estrutura/gestão - setores por área de conhecimento dificultam o desempenho dos processos;

- processos/recursos - duplicação de tarefas e recursos utilizados com existência de processos sendo realizados em vários setores;

- pessoas/treinamento - pessoas não sendo utilizadas em atividades nas quais mais agregam valor; especialização e não multifuncionalidade;

- espaço físico - estrutura e arranjo físicos atual dificultam o desempenho.

Além das questões globais, algumas situações específicas a determinados processos, porém igualmente importantes, foram apontadas:

- automação - menu de exames não ajustado racionalmente entre plataformas;

- processos não automatizados - duplicação de uso dos recursos (pessoas);

- pré-análise na central técnica - sem gestão centralizada, com duplicação de recursos;

- gestão de estoques - estoques elevados (insegurança de reposição); 


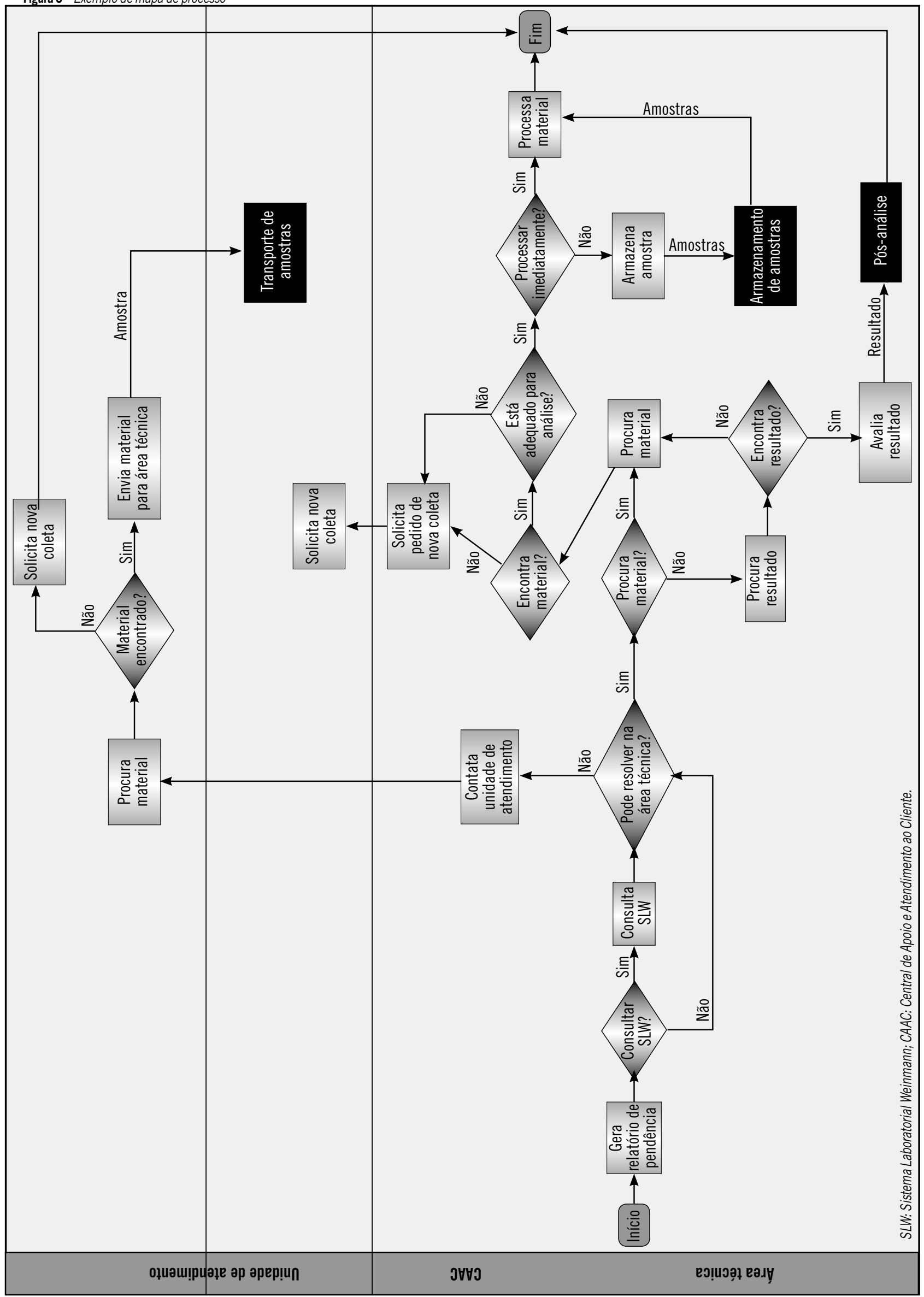


- controle de qualidade - sem gestão específica; falta de padronização entre setores;

- armazenamento de amostras - dificuldade para acessar após processamento; duplicação de recursos (pessoas, equipamentos etc.);

- $\quad$ sistema - não prevê rastreabilidade de amostras após realização dos exames; não permite maior automatização da liberação de resultados (autoverificação); não suporta partes do processo (cálculos etc.) e processos de controle da qualidade analítica;

- hemoterapia - utilização concomitante de dois sistemas informatizados, gerando processos diferentes e prejudicando a gestão e a rastreabilidade das operações;

- manutenção - falta de visão de "gestão de equipamentos" (gestão atual apenas operacional);

- informações a clientes - acesso das unidades de atendimento direto à produção, prejudicando a operação na central técnica;

- logística de transporte de amostras - central técnica não atua diretamente na definição das rotinas de "viagens", não adequando estas a suas necessidades (fluxo e recursos).

Todos os resultados do mapeamento dos processos atuais ("Como é") citados anteriormente foram apresentados para a diretoria da empresa ao final dessa fase do projeto.

\section{Resultados relacionados com os novos processos ("Como será")}

Após a aprovação e as considerações da diretoria quanto ao diagnóstico da fase de mapeamento dos processos até então executados na central técnica do laboratório, as desconexões identificadas nos processos e as sugestões de melhoria geradas foram analisadas e priorizadas visando à proposição de novos processos. Estes seriam gerados a partir do redesenho dos processos executados até o momento, considerando as melhorias identificadas na fase de mapeamento, e alinhados ao atendimento de premissas referentes a maior nível de agregação de valor a clientes e empresa, maior flexibilidade dos processos às alterações de demanda, tecnologias e exigências específicas do mercado, redução de custos e melhor utilização de recursos.

Atendendo a essas premissas, cada processo foi sequencialmente analisado e redesenhado, gerando um plano de ação para a implementação de cada novo processo. Para cada novo processo proposto, um mapa de processo foi gerado ("Como será"), com maior nível de detalhamento do que o apresentado pelo mapa "Como é".

Como exemplo dessa fase de projeto, com o redesenho do processo em vigor e a implementação de novo processo, podem-se citar as alterações realizadas nos processos relacionados com a gestão das amostras biológicas, antes e após seu processamento técnico(7).

Visando melhorar a gestão de amostras durante a execução dos processos na central técnica do laboratório, melhorias foram implementadas em três principais etapas.

Na primeira, foi criada uma área unificada de pré-análise para atender todas as seções (setores) analíticas da central técnica do laboratório. Essa nova área passou a executar quatro principais atividades - recepção e triagem de amostras, inspeção de amostras, centrifugação e aliquotagem - e foi implementada próximo à entrada da central técnica após dois meses de planejamento. Esse planejamento incluiu modificações na área física, desenho do novo processo, treinamento da equipe e implementação de melhorias no sistema laboratorial. Os objetivos foram melhoria na utilização de recursos, disseminação de conhecimentos entre os colaboradores, melhorias na inspeção de amostras e ampliação do nível de segurança no procedimento de aliquotagem de amostras.

Na segunda etapa, implementou-se uma melhoria na gestão de armazenamento de amostras para aquelas que são enviadas para outros laboratórios de referência. Isso foi viabilizado por modificações realizadas em nosso sistema laboratorial. O objetivo foi permitir o rastreamento eletrônico dessas amostras em todas as fases do processo de amostras enviadas para laboratórios de referência ("Feito fora"), assegurando a rastreabilidade e a diminuição na probabilidade de perda dessas amostras. No novo processo, etiquetas de código de barras nas amostras são lidas em duas fases desse processo (no armazenamento e quando as amostras são enviadas para o laboratório de referência). Esses eventos são enviados ao sistema laboratorial, permitindo acesso contínuo ao status das amostras no processo.

$\mathrm{Na}$ terceira etapa, implementou-se um sistema para gestão de armazenamento e recuperação de amostras, que foi disponibilizado pela Data-innovations em seu Instrument Manager ${ }^{\mathrm{TM}}$ e permite rastrear amostras armazenadas após seu processamento analítico. O objetivo foi diminuir o tempo para a recuperação de amostras, reduzindo o tempo dos resultados laboratoriais, assegurando o atendimento dos requisitos clínicos e as necessidades dos clientes. 
Analisando as melhorias implementadas na gestão de amostras biológicas, podem-se evidenciar ganhos significativos com esse redesenho de processos. Os maiores ganhos em custos foram verificados na recuperação de amostras, com mais de $50 \%$ de redução de tempo. Adicionalmente, ganhos significativos foram igualmente obtidos com a diminuição de custos de treinamento com a área de pré-análise unificada e com a redução do número de amostras não encontradas( ${ }^{(8)}$.

Tal como o exemplo da melhoria citada anteriormente na questão da gestão de amostras biológicas, todos os novos processos redesenhados tiveram suporte de uma modificação de estrutura gerencial na central técnica. Além de suportar a implementação de novos processos, a nova estrutura contribuiu para a potencialização dos ganhos obtidos com o projeto de redesenho de processos. Em março de 2008, foi definida e comunicada uma nova estrutura gerencial para os processos técnicos no laboratório. Essa estrutura previa, sob gestão da diretoria técnica, duas áreas de produção principais (automação e não automação) e duas áreas de apoio aos processos técnicos (área científica e manutenção de equipamentos). A nova estrutura, em razão da grande alteração que representava diante da estrutura vigente, foi implantada de forma gradual, visando minimizar resistências e viabilizando uma transição sem afetar negativamente a qualidade e a eficiência dos processos executados. Apoiados nessa nova estrutura, foram implantados gradualmente os novos processos, redesenhados e aprimorados, na rotina da área técnica do laboratório( ${ }^{(9)}$.

\section{Resultados após a implantação (resultados do projeto AT)}

Revisando os resultados do projeto após a implementação das principais ações decorrentes do redesenho de processos técnicos no laboratório, a questão da produtividade se destacava.

Em razão da melhor alocação de recursos nos processos desenvolvidos na central técnica da empresa (alvo desse projeto), pôde ser detectada significativa ampliação no índice de produtividade dessa área.

Entende-se como produtividade a relação entre o número de exames processados na central técnica da empresa e o número de colaboradores alocados nessa mesma área do laboratório (pessoal técnico) em determinado período de tempo (neste estudo, mensal). Antes do início do projeto de redesenho de processos na central técnica do laboratório, a produtividade dessa área era de menos de 4 mil exames por colaborador (janeiro de 2007). Após a finalização do projeto, a produtividade chegou à quase 6 mil exames por colaborador (novembro de 2009). Essa elevação no indicador de produtividade técnica foi alavancada pelos setores de ensaios automatizados, nos quais a produtividade cresceu mais de $39 \%$ entre janeiro de 2007 e novembro de 2009, chegando a mais de 9 mil exames por colaborador ao final de 2009.

Os resultados obtidos pelo projeto em termos de produtividade podem ser contextualizados quando são evidenciadas as informações comparativas do mercado de medicina laboratorial. Um dos programas de benchmarking mais exitosos e reconhecidos no mercado de medicina laboratorial no Brasil é o Programa de Indicadores Laboratoriais da Control-Lab (http://www. controllab.com.br/). O programa Indicadores Laboratoriais é uma ferramenta de gestão desenvolvida em parceria entre a Control-Lab e a Sociedade Brasileira de Patologia Clínica e Medicina Laboratorial (SBPC/ML), com o objetivo de estimular a melhoria contínua nos processos laboratoriais, contribuindo para o aumento da produtividade e da lucratividade do setor ${ }^{(10)}$. Um dos indicadores disponibilizados nesse programa é o Indicador de Produtividade de Pessoal Técnico. A Figura 4 apresenta a evolução desse índice na central técnica do laboratório, entre janeiro de 2007 (antes do início do projeto de redesenho) e novembro de 2009 (após a finalização do projeto), comparando-a com os resultados de mercado apresentados pelo programa de Indicadores Laboratoriais Control-Lab/SBPC-ML.

Analisando os resultados apresentados no comparativo da Figura 4, pode-se evidenciar que, antes do início do projeto de redesenho e durante sua fase inicial (antes da implementação das melhorias nos processos), a produtividade técnica do laboratório estava abaixo do desempenho apresentado pelos $50 \%$ melhores laboratórios do mesmo porte no programa de benchmarking (abaixo da mediana do programa para laboratórios com produção acima de 125.000 exames/mês). A partir de março de 2008, com as primeiras melhorias implementadas nos principais processos, a produtividade técnica elevou-se significativamente (Figura 5), posicionando o resultado do laboratório comparativamente aos demais do mesmo porte no mercado brasileiro de medicina laboratorial, no terceiro quartil (entre os $50 \%$ melhores), chegando a atingir, por dois meses consecutivos, o quarto quartil (em novembro e dezembro de 2008 , entre os $25 \%$ laboratórios com maior produtividade técnica inseridos nesse programa). 


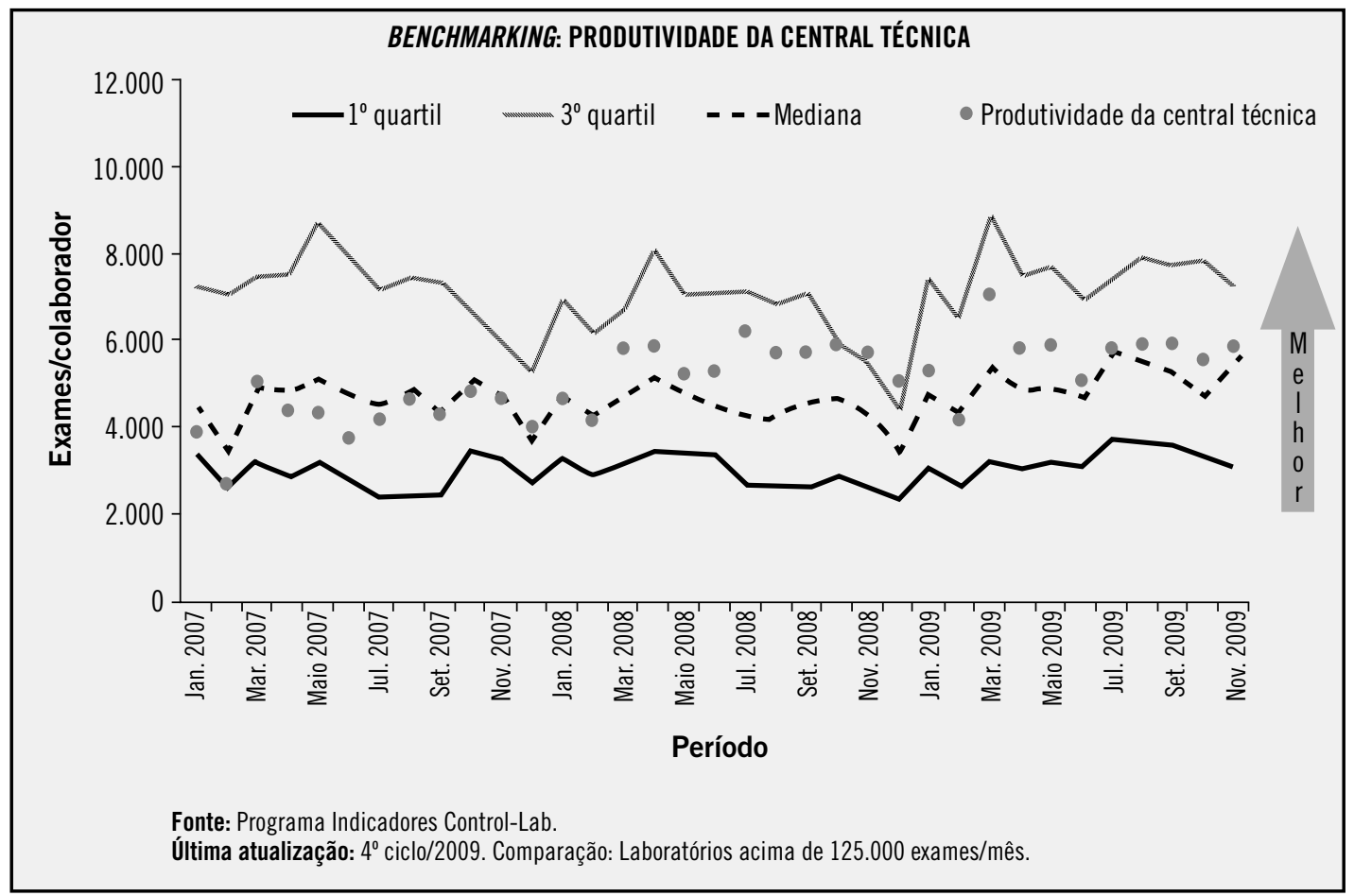

Figura 4 - Evolução da produtividade de pessoal técnico na central técnica do laboratório durante o projeto de redesenho de processos, contextualizada com os resultados do programa Indicadores Laboratoriais Control-Lab/SBPC-ML (benchmarking)

O nível máximo de produtividade técnica no período analisado foi evidenciado em março de 2009, com cerca de 7.000 exames por colaborador, alicerçado pela sazonalidade de atendimento a clientes, que historicamente ocorre nesse período. Cabe salientar que essa elevação de produtividade técnica não foi obtida à custa da diminuição na qualidade dos serviços disponibilizados aos clientes do laboratório, tanto em termos de qualidade intrínseca do produto (laudos corretos) quanto em termos de prazo de entrega ou custos. A absorção da elevação de demanda de clientes sem aumento do quadro de pessoal foi suportada efetivamente pelas melhorias implementadas na gestão e na operação dos processos técnicos.

Além de questões ligadas à melhoria na utilização de recursos, em que, em termos de recursos humanos, podemos evidenciar a produtividade de pessoal técnico, outros resultados com maior ou menor tangibilidade foram obtidos a partir do projeto de redesenho de processos na central técnica do laboratório. Um desses resultados pode ser citado com a maior flexibilidade dos processos, obtida principalmente pela nova estrutura de subáreas na central técnica.

O modelo anterior, com setores divididos segundo disciplinas tradicionalmente formatadas nos laboratórios clínicos até a última década (Bioquímica, Hematologia, Imunologia etc.) e com gestores exclusivos, por vezes implicava em dificuldades para atendimento de demandas especiais de clientes, bem como para outras situações diferenciadas da rotina preestabelecida (alterações de metodologia e/ou equipamentos, falta de reagentes etc.). Nesses eventos, na estrutura tradicional, o tempo de resposta em muitas situações era demasiadamente prolongado para o adequado atendimento dos requisitos de clientes e demais partes interessadas. Por exemplo, em casos de necessidade de transferência de ensaios entre diferentes plataformas (equipamentos), no caso de envolver diferentes setores técnicos, o tempo médio de conclusão dessas alterações chegava a ser cerca de $200 \%$ mais elevado do que o obtido ao final do projeto de redesenho. Esse exemplo pode ser citado como uma das evidências da maior flexibilidade dos processos em atender as demandas dos clientes, obtida com o projeto de redesenho de processos técnicos.

\section{Discussão}

Uma das principais características do projeto de redesenho de processos foi a questão do aprendizado. Em razão de ter sido um dos primeiros projetos na empresa a utilizar essa metodologia, muitos aspectos da metodologia de BPR ainda foram adaptados durante o projeto, visando alinhá-los a determinadas características específicas do projeto, o qual foi sendo "construído" durante sua implementação. Assim, mesmo tendo, por essa razão, impactos previsíveis em 


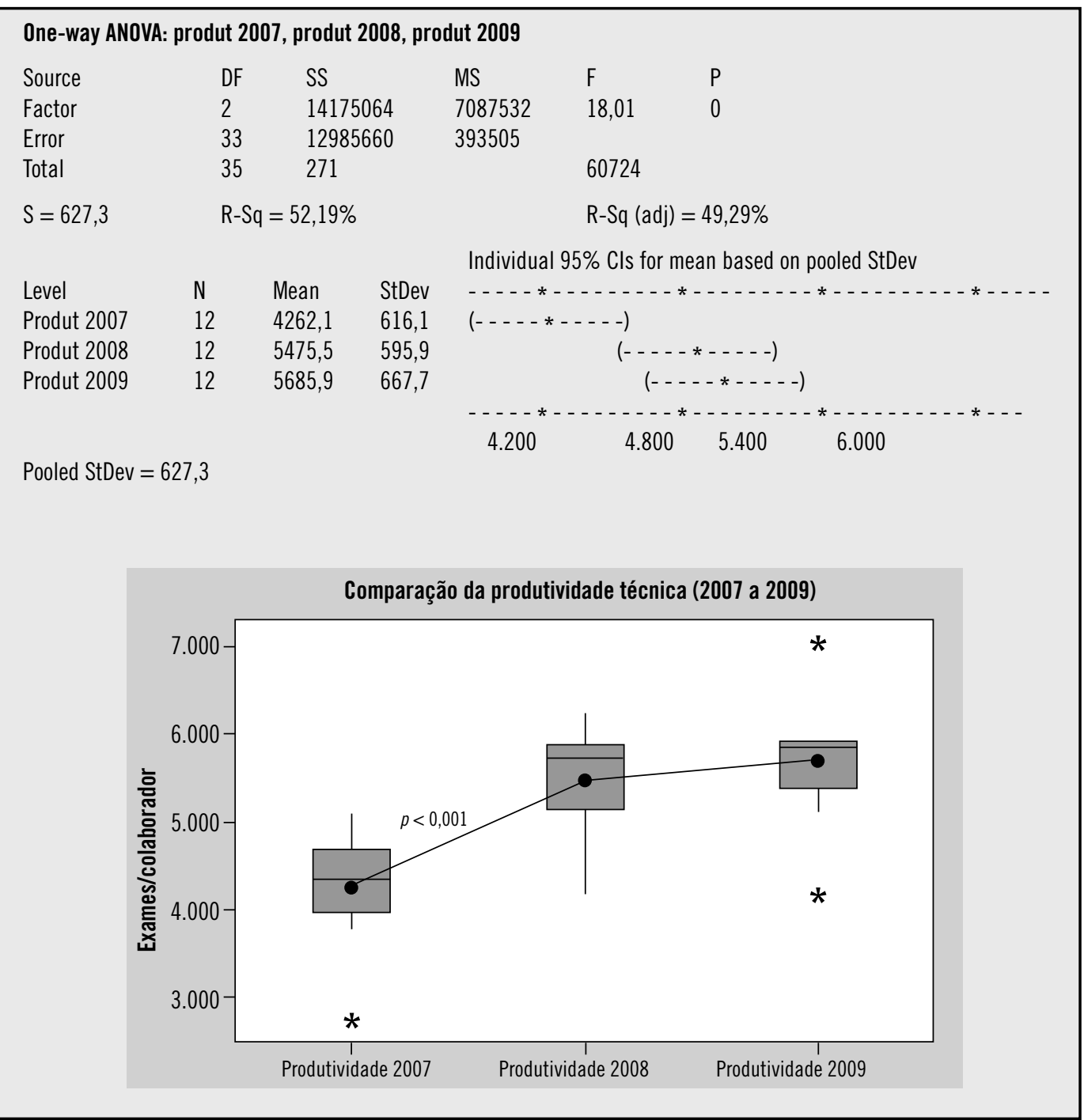

Figura 5 - Avaliação estatística da produtividade de pessoal técnico na central técnica do laboratório durante o projeto de redesenho de processos

termos de tempo e retrabalho, essa característica de condução do projeto permitiu maior adesão e comprometimento do grupo de facilitadores ao trabalho proposto, pois estes se sentiram responsáveis pela construção da metodologia.

Outra questão a ponderar é a do alinhamento estratégico do projeto. Embora suportado e patrocinado pela diretoria da empresa, analisando a primeira fase do projeto, podem-se identificar algumas deficiências de diretrizes estratégicas, visando ao melhor direcionamento do projeto. Assim que identificada, essa questão foi tratada precocemente, ainda na fase prévia ao diagnóstico do "Como é", por meio de reuniões periódicas entre patrocinador e coordenador do projeto. Em razão de esse tratamento ter sido precoce, não houve necessidade de alterações de prazos ou correções drásticas de rumo ao longo do projeto.

Um ponto crítico identificado ao analisarmos a condução do projeto foi a não priorização de medições nos processos já no momento inicial. Na fase "Como é", o foco do trabalho foi direcionado para identificação dos processos, alienação desses processos da estrutura organizacional formal, mapeamento das atividades críticas dos processos e análise de desconexões e possíveis melhorias a serem implementadas. Principalmente na fase de desenho dos novos processos (simulações), foram detectadas as necessidades de medições de desempenho e as características dos processos em vigor na empresa, visando suportar as análises críticas realizadas e a proposição dos novos processos. Essas medições foram implementadas ou aprofundadas já na fase do "Como será", o que, muitas vezes, ocasionou atraso na implementação das melhorias na rotina.

Outro aspecto crítico essencial e que interferiu no andamento do projeto foi a disponibilidade de recursos de tecnologia da informação (TI). Praticamente todos os redesenhos de processos incorporavam melhorias que, de algum modo, exigiam a utilização de tecnologia, isto é, o 
suporte de sistemas informatizados para automatizar e/ou controlar certas atividades, melhorando a utilização dos demais recursos até então empregados e com baixa agregação de valor nos processos anteriormente realizados. A disponibilidade limitada de recursos de TI foi um fator limitante para a implementação das melhorias propostas para os processos, interferindo diretamente no prazo das ações propostas no projeto de novos processos. Essa indisponibilidade de recursos de TI, entretanto, deve ser ponderada em razão de a equipe de TI da empresa estar envolvida em outros projetos de redesenho de processos de outras áreas do laboratório, os quais estavam sendo executados em paralelo ao projeto da central técnica.

Além da disponibilidade limitada dos recursos de TI como restrição do projeto de redesenho de processos da área técnica, a questão referente à definição de sistemas (comunicação das necessidades de melhorias a serem implementadas nos sistemas para suportar os novos processos) foi igualmente um ponto crítico no andamento do projeto. Em muitas situações, as definições de sistemas foram alteradas continuamente, mesmo já durante o desenvolvimento pela equipe de TI, com impacto em termos de retrabalho e prazo de conclusão das tarefas planejadas. Esse aspecto foi mitigado em diversas situações com alinhamentos constantes entre coordenador do projeto e analista de negócio de Tl; fruto desse maior alinhamento houve a geração de mapas de novos processos com maior nível de detalhamento, facilitando a modelagem desses processos para a equipe de TI.

Não desconsiderando todas as ponderações comentadas anteriormente, os resultados do projeto foram tidos como excelentes e com adequada relação custo-benefício, principalmente pela questão relacionada com a nova visão do negócio proporcionada a todos os envolvidos, com nítido realinhamento dos processos técnicos executados aos requisitos de clientes, empresa e demais partes interessadas. Mesmo sendo um projeto quase experimental, visto a falta de experiência anterior de quase todos os envolvidos em projetos semelhantes, os resultados foram expressivos, o que pode ser atribuído a algumas características específicas:

- apoio da alta direção - orientação top-down para resultados;

- visão multidisciplinar e multi-hierárquica - envolvimento no projeto, com níveis similares de possibilidade de contribuição e interferência, de profissionais de diferentes áreas e formações (médicos, bioquímicos, analistas de sistema, psicólogos etc.) e de diferentes níveis hierárquicos (gerentes, supervisores, analistas);
- gestão da mudança - em paralelo, suporte durante todo o projeto da área de Recursos Humanos, atentando para questões relacionadas com a preparação dos profissionais para o processo de mudança gerado pelo redesenho dos processos da área técnica.

\section{Conclusão}

$\mathrm{O}$ atendimento aos requisitos dos clientes é um desafio constante para todas as empresas. Essas necessidades dos clientes, sejam manifestadas formalmente ou não, evoluem continuamente e exigem das empresas adaptações e, por vezes, alterações radicais em seus processos. Existem várias metodologias que podem ser empregadas pelas organizações para implementar melhorias radicais em seus processos. A metodologia de BPR, cuja aplicação no laboratório clínico é discutida neste estudo, é uma das iniciativas para reorientar os processos para o atendimento aos requisitos dos clientes, focando a ampliação do nível de agregação de valor desses processos aos clientes e à empresa.

Conforme demonstrado neste trabalho, a iniciativa de redesenho de processos, se implementada de forma planejada, orientada a resultados e alinhada à estratégia da organização, pode proporcionar resultados significativos para a empresa. Entre eles podemos identificar maior flexibilidade de processos, que permite à empresa maior capacidade de se adaptar continuamente e em curto prazo de tempo às novas exigências de clientes e mercado. Esses resultados também podem ser alcançados pelos laboratórios clínicos, mesmo que estes disponham de recursos limitados para iniciativas desse porte. Projetos de redesenho como o relatado na experiência descrita aqui podem ser adaptados para a aplicação em laboratórios clínicos de vários portes e em diferentes situações competitivas no mercado. Entretanto, a principal exigência para o sucesso de iniciativas como esta é o adequado alinhamento do projeto às necessidades estratégicas do negócio, visando orientar corretamente os processos da organização aos objetivos do negócio e ao nível de serviço exigido pelos clientes-alvo da empresa.

O mercado de medicina laboratorial está cada dia mais competitivo e exige dos laboratórios clínicos flexibilidade, criatividade e gestão efetiva de seus processos. A metodologia de BPR é uma das ferramentas disponíveis para o laboratório clínico, visando à implementação de um sistema de gestão por processos, essencial para assegurar o alinhamento dos processos aos requisitos dos clientes, com ganhos adicionais associados à utilização inteligente de recursos. 


\section{Referências}

1. GRAHAM, M.; LEBARON, M. The horizontal revolution. San Francisco: Jossey-Bass, 1994.

2. GONÇALVES, J. As empresas são grandes coleções de processos. Revista de Administração de Empresas, v. 40, n. 1, p. 6-19, jan./mar. 2000.

3. GONÇALVES, J. Processo, que processo? Revista de Administração de Empresas, v. 40, n. 4, p. 8-19, out./dez. 2000.

4. BERLITZ, F. de A. Controle da qualidade no laboratório clínico: alinhando melhoria de processos, confiabilidade e segurança do paciente. J Bras Patol Med Lab, v. 46, n. 5, p. 353-63, 2010.

5. MENDES, J. V.; ESCRIVÃO FILHO, E. Sistemas integrados de gestão ERP em pequenas empresas: um confronto entre o referencial teórico e a prática empresarial. Gest Prod São Carlos, v. 9, n. 3, 2002.

6. VAN DER AALST, W. M. P.; VAN HEE, K. M. Framework for business process redesign. In: CALLAHAN, J. R. (Ed.) Proceedings of the fourth workshop on enabling technologies: infrastructure for collaborative enterprises (WETICE 95). Berkeley Springs; IEEE Computer Society Press, p. 36-45, abr. 1995. Disponível em: <http://is.tm. tue.nl/staff/wvdaalst/publications/p26.pdf>. Acesso em: 9 nov. 2010.

7. BERLITZ, F. de A. Samples management process improvement in a clinical laboratory. 2009 American Association for Clinical Chemistry Annual Meeting. Abstract A-83. Chicago/IL.

8. BERLITZ, F. de A. Otimização do processo de gestão de amostras em um laboratório clínico. 2009. Trabalho apresentado ao $43^{\circ}$ Congresso Brasileiro de Patologia Clínica e Medicina Laboratorial, tema livre n² 233, Belo Horizonte (MG), ago. 2009. Disponível em: <http://www. publicacoesweinmann.com.br/2009/08/otimizacao-doprocesso-de-gestao-de.html>. Acesso em: 3 dez. 2010.

9. BERLITZ, F. de A. Redesenho de processos técnicos e adequação de estrutura gerencial: alinhando pessoas e processos para aumento de produtividade e preservação do conhecimento científico. 2008. Trabalho apresentado ao $42^{\circ}$ Congresso Brasileiro de Patologia Clínica e Medicina Laboratorial, tema livre n 8, São Paulo (SP), jul. 2008.

10. CONTROLLAB. Indicadores laboratoriais. Folder 2010. Disponível em: <http://www.controllab.com.br/pdf/ folder_indic_2010.pdf>. Acesso em: 1 dez. 2010. 